\title{
Research on the Chinese Government Environmental Information Disclosure System
}

\author{
Yuxue Liang ${ }^{1}$ \\ ${ }^{1}$ Law Major of Zhengzhou University, Jinshui District, Zhengzhou City, Henan Province, China \\ * Corresponding author email: 1035096335@qq.com
}

\begin{abstract}
As the main collector and controller of environmental information, the government has become the main body of environmental information disclosure. A complete government environmental information disclosure system requires special legislation, a wide range of disclosure subjects, and detailed disclosure content. Although China has already had actual operations in legislation and practice, its system construction is not perfect in the above three aspects. This article starts from the three aspects of legislation overview, disclosure subject, and disclosure content, analyzes the shortcomings of China's existing system, and draws on foreign countries' advanced legislation experience on related systems. Combining with China's national conditions, it puts forward suggestions on the further development of China's legislation on the government's environmental information disclosure system.
\end{abstract}

Keywords: Environmental Information Disclosure System; Legislative System; Disclosure Subject; Disclosure Content

\section{RESEARCH ON THE LEGISLATIVE SYSTEM OF THE CHINESE GOVERNMENT'S ENVIRONMENTAL INFORMATION DISCLOSURE SYSTEM}

The choice of the legislative system is a basis for the construction of the government's environmental information disclosure system. To build a complete government environmental information disclosure system, we must first study the legislative system on this system as a whole, and grasp the legal basis that constitutes the government environmental information disclosure system from a macro perspective.

\subsection{The legislative status quo of the legislative system of the environmental information disclosure system of the Chinese government}

China's environmental information disclosure system has gone through a process from scratch, from more to less. The specific legislation is mainly reflected in the following regulatory documents:

\subsubsection{Provisions on the disclosure of government environmental information in the Basic Environmental Law}

Article 53 and Article 54 of the 2015 "Environmental Protection Law" stipulate the subject of rights and obligations of government environmental information disclosure; Article 56 stipulates that the department responsible for the environmental impact assessment of a construction project shall make the full text of the environmental assessment document public. Article 57 stipulates that the public has the right to report the dereliction of duty by the subject of the obligation; Article 68 provides for the accountability system.

\subsubsection{Provisions on the disclosure of government environmental information in the separate environmental laws}

Articles 20 and 23 of the 2000 "Air Pollution Prevention and Control Law" stipulate that the administrative department shall regularly publish a bulletin on the air environment quality status; Article 17 of the 2002 "Cleaner Production Promotion Law" stipulates that the list of enterprises that discharge pollution exceeding the standard shall be published on a 
regular basis; Article 11 of the 2002 "Environmental Impact Assessment Law" stipulates that the special plan preparation agency shall solicit public opinions on plans that directly involve the public's environmental rights and interests before submitting the draft plan for approval. Article 19 of the "Water Pollution Prevention and Control Law" revised in February 2008 stipulates the publication of relevant matters of governments, enterprises and institutions that violate this law; Article 17 of the "Recycling Economy Promotion Law" in August 2008 stipulates that the state will regularly announce the main statistical indicators to the public.

\subsubsection{Provisions on the disclosure of government environmental information in administrative regulations}

The 2007 "Government Information Disclosure Regulations" detailed and clarified the specific content of government information disclosure, and stipulated the obligations of government agencies at all levels to provide corresponding information to the public, and clarified the methods, procedures, supervision and relief of disclosure.

\subsubsection{PROVISIONS ON GOVERNMENT ENVIRONMENTAL INFORMATION DISCLOSURE IN OTHER REGULATORY DOCUMENTS}

The 2005 "Decision on Implementing the Scientific Outlook on Development and Strengthening Environmental Protection" and the 2013 "Notice on the Arrangements for Leading Current Government Information Disclosure" have improved the government environmental information disclosure system from different aspects.

\subsection{The legislative system of the Chinese government's environmental information disclosure system is imperfect and has a low level of effectiveness}

The environmental information disclosure system of the Chinese government reflects the deficiencies of the imperfect legislative system and the low level of effectiveness. First of all, from the perspective of the overall legal system, China's relevant legislation has not formed a system. Although there is a "Government Information Disclosure Article". Special administrative regulations such as "Regulations", but their levels are lower, which conflict with the higher-level "Secrecy Law". Moreover, China has given administrative agencies too much discretion in measuring privacy issues, making relevant environmental information unable to be disclosed in a timely and effective manner. For example, in 2013, public welfare lawyer Dong Zhengwei applied to the Ministry of Environmental Protection to disclose information on the state of soil pollution across the country. However, the Ministry of Environmental Protection replied in the "Notice of Disclosure of Government Information" that the most critical soil pollution status information was refused to be disclosed on the grounds of "state secrets" [1].

Secondly, from the perspective of the level of effectiveness of the law, only the "Environmental Protection Law" in China belongs to the law, and the rest are administrative regulations or separate regulations, and the level of effectiveness is not as high as that of the law. The problem caused by the lack of high-level legislation is that the discretionary power of the administrative agency is not reasonably restricted and is easily abused, which leads to the damage to the citizen's right to know.

Table 1: From 2012 to 2014, some provinces of China's government environmental information disclosure status table based on application

\begin{tabular}{|l|l|l|}
\hline \multicolumn{3}{|l|}{ Disclosure of Beijing government environmental information upon application } \\
\hline Years & Total & Agree to Disclosure \\
\hline 2012 & 97 & 43 \\
\hline 2013 & 116 & 40 \\
\hline 2014 & 184 & 81 \\
\hline Disclosure of Shanghai government environmental information upon application \\
\hline Years & Total & Agree to Disclosure \\
\hline 2012 & 80 & 32 \\
\hline 2013 & 98 & 50 \\
\hline 2014 & 120 & 59 \\
\hline Environmental information disclosure of Henan government upon application \\
\hline Years & Total & Agree to Disclosure \\
\hline 2012 & 15 & 9 \\
\hline 2013 & 38 & 10 \\
\hline
\end{tabular}




\begin{tabular}{|c|c|c|}
\hline 2014 & 40 & 15 \\
\hline \multicolumn{3}{|c|}{ Disclosure of environmental information of the Jilin government upon application } \\
\hline Years & Total & Agree to Disclosure \\
\hline 2012 & 14 & 1 \\
\hline 2013 & 21 & 19 \\
\hline 2014 & 20 & 5 \\
\hline \multicolumn{3}{|c|}{ Hainan Government Environmental Information Disclosure According to Application } \\
\hline Years & Total & Agree to Disclosure \\
\hline 2012 & 17 & 13 \\
\hline 2013 & 17 & 17 \\
\hline 2014 & 17 & Unknown \\
\hline \multicolumn{3}{|c|}{ Disclosure of Xinjiang government environmental information upon application } \\
\hline Years & Total & Agree to Disclosure \\
\hline 2012 & 2 & 2 \\
\hline 2013 & unknown & unknown \\
\hline 2014 & 4 & 2 \\
\hline
\end{tabular}

(Data source: 2012-2014 annual reports of the Ministry of Environmental Protection and the Provincial Environmental Protection Agency)

As shown in the above table, the ratio of the government's approval of citizens' applications for disclosure of environmental information to the total amount of citizens' applications for disclosure of information is relatively low. The realization of the public's right to know the environment mainly depends on two ways: One is that government departments and relevant enterprises and institutions actively disclose environmental information in accordance with the mandatory requirements of the law; The second is the public applying for government departments to disclose relevant environmental information. In short, the realization of the public's right to know the environment mainly depends on the disclosure of government environmental information [2]. Due to China's lack of relevant high-level legislation to restrict the discretionary power of administrative agencies, and the lack of relevant supporting laws to protect it, citizens' right to know is difficult to guarantee under such circumstances.

\subsection{Suggestions on the improvement of the Chinese government's environmental information disclosure legislation system}

As far as the overall legal system is concerned, China should form an interlocking legislative system in legislation, update normative legal documents in a timely manner, and avoid conflicts between different levels of normative legal documents.

As far as the level of effectiveness of the law is concerned, the author believes that the legislative conditions of the Environmental Information Disclosure Law are still immature. In the form of administrative regulations, an environmental information disclosure system can be established as soon as possible, which can meet the urgent need for environmental information disclosure legislation in practice. From the perspective of legal effect, a system similar to the disclosure of environmental information should be practiced first, followed by legislation. Enacting administrative regulations first and then transforming them into law is not only conducive to the improvement and maturity of the legal content, but also conducive to the accumulation of experience and the final implementation of the law. Therefore, the "Measures for Disclosure of Environmental Information (Trial)" that we currently release is in line with reality. The State Council will then formulate the "Regulations on Disclosure of Environmental Information," and after repeated practice, the "Law on Disclosure of Environmental Information" will be formulated when conditions are ripe.

\section{RESEARCH ON THE SUBJECT OF CHINESE GOVERNMENT ENVIRONMENTAL INFORMATION DISCLOSURE}

\subsection{The current legislative status of the subjects of environmental information disclosure}

As far as the subject of rights is concerned, the subject of rights in the government's environmental information disclosure legislation is mainly the public third party and the subject of supervision. The latest amendments to the Environmental Protection Law, the Regulations on Disclosure of Government Information and the Measures on Disclosure of Environmental 
Information (Trial) both adhere to the same standards in defining the subject of rights. That is, citizens, legal persons or other organizations all have the right to obtain environmental information.

As far as the subject of obligation is concerned, the subject of obligation in government environmental information disclosure legislation is the government. According to China's current government environmental information disclosure laws and regulations: The government, as the subject of obligation, specifies the environmental protection departments of governments at and above the county level in the "Regulations on Disclosure of Government Information" and "Measures on Disclosure of Environmental Information (Trial)".

\subsection{The main body of Chinese government environmental information disclosure is relatively limited}

From the perspective of the subject of rights, the subject of the rights of Chinese government information disclosure is subject to nationality restrictions. That is, foreigners cannot apply to the environmental protection department to disclose environmental information, and there are a small number of organizations that comply with the newly revised Environmental Protection Law. It can be seen that the consequence of the restriction of the rights subject of Chinese government information disclosure is that it cannot effectively realize the participation of public welfare organizations in environmental information disclosure and give play to the supervisory role of social organizations.

From the perspective of the subject of obligation, China's subject is limited to environmental protection departments at all levels, and there is no requirement that other departments also bear related responsibilities. In view of the current embarrassment of the role of environmental protection departments in the government's environmental information disclosure, the environmental information held by various departments cannot be managed uniformly. Once there is a pollution incident caused by the unfavorable disclosure of environmental information, the environmental protection department will naturally become the target of criticism [3]. This point has not been substantially changed in the latest revision of the Environmental Protection Law, and the content of the original provisions is still retained, only the order has been changed. Disclosure of environmental information is not only the responsibility of environmental protection authorities, but also requires the joint cooperation of other government departments. The scope of the main body of government environmental information disclosure at this stage is far from the public's demand for environmental information disclosure.

It can be seen that China does not try its best to let more people get as comprehensive environmental information as possible, but only to ensure that Chinese citizens, legal persons and specific organizations are informed of the environmental information held by the environmental protection department.

\subsection{Suggestions for the expansion of the main body of environmental information disclosure by the Chinese government}

China should follow two principles when expanding the scope of the main body of government information disclosure: The first is the responsibility principle of the government for the management of social life. The second is the principle of diversity of the public's demand for environmental information.

First, adjust the scope of the subject of government information disclosure, that is, the public third party. By inspecting countries with advanced government environmental information disclosure systems, we can find that the scope of disclosure subjects is relatively large, which can protect the public's right to know. For example, there are no nationality restrictions in the United States, foreigners can also apply to relevant departments to open environmental information, and there are no restrictions on "other organizations". This means that any organization can apply for the US government to disclose environmental information. Therefore, these practices can be used for reference, combined with China's national conditions, and taken into consideration in terms of government administrative costs and information security. Thus, it is defined as "including Chinese citizens, legal persons and other organizations, as well as foreigners and stateless persons residing in China."

Second, adjust the scope of the government that is the subject of government information disclosure obligations. At present, China's departmental regulation-level legislation cannot restrict the unexpected departments of the Ministry of Environmental Protection. Therefore, it is necessary to determine at the legislative level that other subjects that have the same obligation to disclose environmental information as the Ministry of Environmental Protection are all legal subjects. The prerequisite for becoming a universal right that can be protected by the system is to determine the right through the law [4]. 


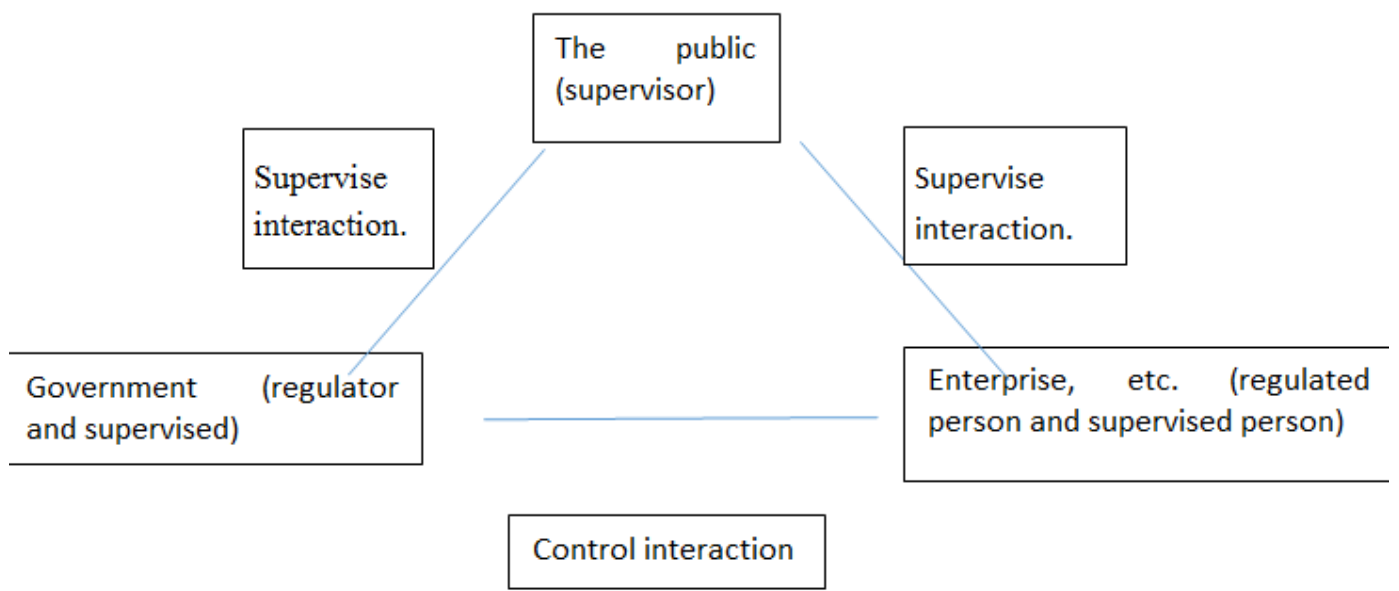

Figure 1: The interactive equilateral triangle of environmental protection subjects

As shown in the figure above, the purpose of China's final adjustment of the scope of disclosure is to form a benign interaction with each other, that is, the three forces play a role in mutual coordination and restriction. This article mainly studies the government's environmental information disclosure behavior, so it focuses on the supervision relationship formed between the third party and the government. In a structured system of benign interaction, the government not only performs regulatory functions, but also supervises and regulates the environmental information disclosure of enterprises and organizations, thereby promoting the environmental performance of relevant entities; At the same time, the government itself is also faced with inspection, assessment and public supervision, and needs to provide a wider range and higher standard of environmental information disclosure in order to optimize the environmental policy and ecological governance system. Therefore, it is necessary to expand the rights and obligations of government environmental information disclosure. In this way, the public can better supervise the government, establish a range of vertical and horizontal interlaced obligations, and realize the omni-directional and multi-level requirements of government environmental information.

\section{RESEARCH ON THE CONTENT OF CHINESE GOVERNMENT ENVIRONMENTAL INFORMATION DISCLOSURE}

\subsection{The current legislation status of the Chinese government's environmental information disclosure content}

Regarding the aspects that should be made public, China adopts an enumeration formula. E.g.: Article 11 of the "Measures for Disclosure of Environmental Information (Trial)" lists the environmental information that environmental protection agencies should proactively disclose. In addition, the Air Pollution
Prevention and Control Law, the Soil and Water Conservation Law, etc. also have general provisions in this regard.

Regarding the aspects that are not disclosed, the "Guidelines for Disclosure of Environmental Protection Information" stipulate that state secrets, business secrets, personal privacy, ongoing investigations and information related to administrative law enforcement shall not be disclosed. Article 12 of the Measures for Disclosure of Environmental Information (for Trial Implementation) clearly stipulates the confidentiality review mechanism [5].

\subsection{The scope of the disclosure of environmental information by the Chinese government is narrow and unclear}

In terms of information that should be disclosed From an overall point of view, China adopts the combined use of generalization and enumeration, resulting in the limitations of its text that cannot exhaust all types of information. Obviously, this approach cannot deal with the status quo. By examining the legislation of advanced countries in the world, it can be found that most of them follow the principle of "opening as the principle and non-opening as the exception". For example, in addition to all environmental-related information held by various departments, what the United States needs to disclose is the information holders, the relevant information after entering the company to inspect the relevant facilities, and the method of obtaining this information, and so on. From a specific point of view, as far as the information content of key pollutant companies is concerned, the United States requires companies to disclose the relevant information of toxic and hazardous chemical substances and enter the database for citizens to consult. However, China only requires the environmental protection department to disclose the list of various companies, and completely relies on the self-consciousness of the companies to disclose the emissions, equipment testing 
and other information of the companies involved. As far as EIA information is concerned, the United States has not solved the problem [6]. of "limited information, slow time, and complex content". In 1996, it proposed the three principles of "effective, timely, and easy to understand". The United States requires that EIA information should not contain too many technical terms, but should be as easy to understand as possible, so that the public can participate in it and express opinions [7]. In contrast to China, the information disclosed by environmental protection departments at all levels is only general information such as project names and locations. Therefore, the information that China wants to disclose still needs to be improved.

As for information that is not disclosed, the scope of China's non-disclosure is too general and vague, and the discretionary power is relatively large. Although the "Environmental Information Disclosure Measures (Trial)" generally stipulates five types of non-disclosure situations. However, there is no clear definition of these situations, and no specific definitions are made on matters that are not to be disclosed. This leads to considerable discretionary power for the administrative organs [8].

\subsection{Detailed recommendations on the scope of disclosure of environmental information content by the Chinese government}

The author believes that a positive summary and a negative enumeration model should be adopted in the special environmental information disclosure legislation, and the three aspects of non-disclosure should be refined and the scope should be clarified.

In terms of matters that should be disclosed, the scope of environmental information disclosure should include all information related to environmental protection, that is, it should include the status of environmental elements, the impact of human activities on the environment, the measures taken by humans, and the impact of the environment on humans category. On the basis of full consideration of national, social and economic security, legislation shall be adopted to provide more detailed regulations on the scope of disclosure to broaden the scope of government environmental information disclosure. For example, the disclosure of environmental administrative punishment information must include information such as the name of the company, the reason for the punishment, and the result of the punishment. It is not possible to refuse disclosure on the grounds of involving trade secrets, and to prevent local legal entities from supervising them.

Regarding matters that are not to be disclosed, first of all, we can learn from the balance of interests judgment standard in the United States to limit matters that are not to be disclosed. There are: State secrets, business secrets and personal privacy. While improving the environmental information disclosure system, the connotation and extension of the above concepts are clearly defined in the relevant legislation. Secondly, it addresses the issue of greater discretionary power that administrative agencies have when judging whether a certain information is a matter that is not to be disclosed. On the basis of the specific circumstances that are not disclosed in the legislation, other circumstances that are not to be disclosed must be controlled with a "dangerous level of harm to the public interest."

\section{CONCLUSION}

Information disclosure is the prerequisite and foundation for building a transparent government and promoting citizen participation. China's government environmental information disclosure system still has various imperfections. The legislative system is imperfect and the level of effectiveness is low, the main body of disclosure is relatively limited, and the scope of disclosure is relatively narrow. Therefore, it is proposed to improve the legislative system, expand the scope of disclosure subjects, and refine the scope of disclosure content.

\section{REFERENCES}

[1] Refer to Zhang Zewei, Ni Yuanjin, etc.: "Applying for Environmental Information Disclosure Is More Difficult than Getting to the Sky? ", "Xinhua Daily Telegraph", June 7, 2013.

[2] Refer to Yan Houfu: "Between Openness and Non-disclosure: The Conflict and Balance between the Public's Right to Know the Environment and the Government's Right to Manage Environmental Information", Journal of Shanghai University (Social Science Edition), March 2, 2017, p. 100.

[3] Refer to Wang Xi and Deng Yang: "From "Unified Supervision and Management" to "Comprehensive Coordination"-Comment on Article 7 of the Environmental Protection Law of the People's Republic of China", "Journal of Social Sciences of Jilin University" 2011, Issue 6. Page 85.

[4] Refer to Han Dayuan and Yang Fuzhong: "A Discussion on the Legalization of Government Information Disclosure in my country", Journal of National School of Administration, Issue 2, 2004, p. 62.

[5] Article 12 of the Measures for Disclosure of Environmental Information (for Trial Implementation): "Environmental protection departments shall establish and improve the confidentiality review mechanism for the release of 
government environmental information. Clarify the review procedures and responsibilities. Before disclosing government environmental information, the environmental protection department shall conduct a review in accordance with the Law of the People's Republic of China on Keeping State Secrets and other laws, regulations and relevant national regulations. Environmental protection departments shall not disclose government environmental information involving state secrets, commercial secrets, and personal privacy. However, government environmental information involving commercial secrets and personal privacy that may have a major impact on the public interest may be disclosed with the consent of the right holder or the environmental protection department. When the environmental protection department is not sure whether the government environmental information can be disclosed, it shall report to the relevant competent department or the confidentiality department at the same level for determination in accordance with laws, regulations and relevant national regulations".

[6] Refer to Adam N. Bram, "Public Participation Need Not Contribute to Environmental Injustice", 5 Temple Political \& Civil Rights Law Review 145, Spring, 1996, pp. 36-40.

[7] Refer to Nancy Perkins Spyke, "Public Participation in Environmental Decision-making at the New Millennium: Structuring New Sphere of Public Influence", 26 Boston College Environmental Affairs Law Review 263, Winter, 1999, pp.28-29.

[8] The "Tacitus Trap" is named after Tacitus, a historian in ancient Rome. In layman's terms, it means that when a government department loses its credibility, whether it is telling the truth or lies, doing good or bad things, it will be regarded as telling lies and doing bad things. 